\title{
ARTICLE \\ Unique treatment potential of cannabidiol for the prevention of relapse to drug use: preclinical proof of principle
}

Gustavo Gonzalez-Cuevas ${ }^{1,4}$, Remi Martin-Fardon (iD) ${ }^{1}$, Tony M. Kerr ${ }^{1}$, David G. Stouffer ${ }^{1}$, Loren H. Parsons ${ }^{1}$, Dana C. Hammell ${ }^{2}$, Stan L. Banks ${ }^{3}$, Audra L. Stinchcomb ${ }^{2}$ and Friedbert Weiss (iD)

Cannabidiol (CBD), the major non-psychoactive constituent of Cannabis sativa, has received attention for therapeutic potential in treating neurologic and psychiatric disorders. Recently, CBD has also been explored for potential in treating drug addiction. Substance use disorders are chronically relapsing conditions and relapse risk persists for multiple reasons including craving induced by drug contexts, susceptibility to stress, elevated anxiety, and impaired impulse control. Here, we evaluated the "anti-relapse" potential of a transdermal CBD preparation in animal models of drug seeking, anxiety and impulsivity. Rats with alcohol or cocaine self-administration histories received transdermal CBD at $24 \mathrm{~h}$ intervals for 7 days and were tested for context and stress-induced reinstatement, as well as experimental anxiety on the elevated plus maze. Effects on impulsive behavior were established using a delay-discounting task following recovery from a 7-day dependence-inducing alcohol intoxication regimen. CBD attenuated context-induced and stress-induced drug seeking without tolerance, sedative effects, or interference with normal motivated behavior. Following treatment termination, reinstatement remained attenuated up to $\approx 5$ months although plasma and brain CBD levels remained detectable only for 3 days. CBD also reduced experimental anxiety and prevented the development of high impulsivity in rats with an alcohol dependence history. The results provide proof of principle supporting potential of CBD in relapse prevention along two dimensions: beneficial actions across several vulnerability states and long-lasting effects with only brief treatment. The findings also inform the ongoing medical marijuana debate concerning medical benefits of non-psychoactive cannabinoids and their promise for development and use as therapeutics.

Neuropsychopharmacology (2018) 43:2036-2045; https://doi.org/10.1038/s41386-018-0050-8

\section{INTRODUCTION}

There is debate as to the legitimate medical use of marijuana and cannabinoids. Various medical benefits of cannabinoids have been described (e.g., [1]). Nonetheless, prescription of Cannabis sativa for medical use faces major challenges (e.g., [1, 2]). However, C. sativa contains distinct non-psychoactive, non-addictive constituents that offer medical benefit and may be more readily amenable for use as therapeutics. Among these, cannabidiol (CBD) is a major candidate $[2,3]$. CBD (Epidiolex ${ }^{\circledR}$ ) is under clinical investigation for the treatment of childhood seizures related to Dravet Syndrome, and a CBD-containing formulation (Sativex ${ }^{\circledast}$ ) is currently in use to treat spasticity and neuropathic pain in multiple sclerosis $[4,5]$.

Recently, CBD has received attention for potential in treating drug and alcohol addiction [2]. But, to date, both clinical $[6,7]$ and preclinical [8-11] studies yielded mixed results such that the promise of $\mathrm{CBD}$ as an intervention for addictive disorders requires further scrutiny [12]. Leads exist in literature pointing toward pharmacotherapeutic potential of CBD, particularly for a spectrum of indications relevant for the prevention of relapse to drug use. Drug addiction is a chronic, relapsing brain disease [13, 14], and drug addicts remain at risk for relapse for multiple reasons. Prominent among these are susceptibility to stress, craving induced by drug contexts, heightened anxiety, and impaired impulse control. Several findings suggest that CBD may be effective for targeting these risk states. First, many of CBD's reported general pharmacological effects imply therapeutic benefit also for affective changes and the compulsive nature of drug seeking in addicted individuals. These include effects consistent with anxiolytic [15, 16], stress-reducing [15, 17, 18], antidepressant [19], and anti-compulsive [20] activity. Second, CBD exerts many of its neurobiological effects [21-23] within the brain circuitry that mediates drug craving and seeking elicited by drugrelated environmental contexts and stress [24]. Third, CBD has neuroprotective actions [25] that extend to attenuation of alcoholinduced neurodegeneration [26], the latter likely contributing to impulse control deficits in alcoholics [27]. Considering this profile of behavioral and neuropharmacological effects as well as CBD's actions within the addiction neurocircuitry, we predicted that CBD has therapeutic potential relevant for multiple conditions that underlie relapse risk, including craving induced by drug-related environmental contexts, susceptibility to stress, heightened anxiety and, possibly, impaired impulse control. Guided by this hypothesis we sought to establish preclinical proof of principle toward a large-spectrum potential of CBD in relapse prevention. To this end, we used rats with histories of alcohol or cocaine selfadministration to determine (a) whether CBD attenuates the

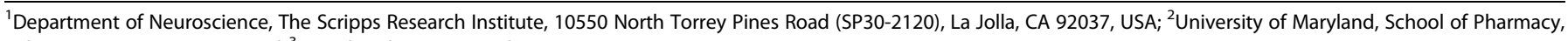
Baltimore, MD 21201, USA and ${ }^{3}$ Zynerba Pharmaceuticals, Devon, PA 19333, USA

Correspondence: Friedbert Weiss (bweiss@scripps.edu)

${ }^{4}$ Present address: Department of Psychology, European University of Madrid, School of Biomedical Sciences, Madrid 28670, Spain

Received: 31 August 2017 Revised: 29 January 2018 Accepted: 14 March 2018

Published online: 22 March 2018 
capacity of both drug-related contextual stimuli and stress to elicit drug seeking in animal models of relapse, (b) reduces experimental anxiety during abstinence, and (c) reverses impaired impulse control associated with a history of alcohol dependence.

\section{MATERIALS AND METHODS}

Animal use and care

Subjects were Male Wistar rats (Charles River, Wilmington, MA), pair-housed on a $12 \mathrm{~h}$ (Lights off at 20:00) light/dark cycle in a temperature and humidity controlled vivarium with ad libitum availability of food and water, except where noted otherwise. All procedures were conducted in strict adherence to the National Institutes of Health Guide for the Care and Use of Laboratory Animals and approved by the Institutional Animal Care and Use Committee of The Scripps Research Institute.

\section{Drugs}

CBD was administered transdermally to enhance translational relevance regarding future therapeutic applications. The clinical potential of CBD when administered orally is constrained to some extent by low ( 6\%) bioavailability [28] and potential for conversion into psychoactive cannabinoids in gastric fluid [29]. However, we have identified the transdermal route of administration as an effective delivery method that eliminates both these limitations and produces stable and sustained plasma CBD levels $[26,30]$. Transdermal CBD was prepared as a fast-drying $(<5 \mathrm{~min})$ $2.5 \%$ hydroalcoholic proprietary gel formulation $(2.5 \mathrm{~g} \mathrm{CBD} / 100 \mathrm{~g}$ gel) containing a non-toxic skin biocompatible permeation enhancer (Transcutol ${ }^{\circledR} \mathrm{HP}$, Gattefosse, USA). The gel was applied to a shaved area of skin outside the animals' reach (shoulder blades). Following application, rats were single-housed for $4 \mathrm{~h}$ before behavioral testing or returned to group housing on nontest days.

Ethyl alcohol was diluted in tap water. Cocaine hydrochloride (National Institute on Drug Abuse, Bethesda, MD) and yohimbine hydrochloride (Sigma) were dissolved in sterile physiological saline.

\section{Equipment}

Standard behavioral equipment was used as previously described (alcohol self-administration and reinstatement [31], cocaine selfadministration and reinstatement [32], experimental anxiety/ elevated plus maze (EPM) [33], locomotor activity [32], impulsive choice [34]). Drug self-administration and reinstatement tests were conducted in sound-attenuated operant conditioning chambers equipped with two retractable levers, house and cue lights, and a speaker for presentation of auditory stimuli. A syringe pump, activated by responses at a designated lever, delivered $0.1 \mathrm{ml}$ of liquid reinforcers into a $0.15 \mathrm{ml}$ drinking reservoir or produced intravenous infusion of cocaine in a volume of $0.1 \mathrm{ml}$ over $4 \mathrm{~s}$. For delay-discounting tests, operant conditioning chambers were equipped with two nose-poke operanda that delivered $45 \mathrm{mg}$ food pellets [34]. Locomotor activity was measured in metal wire hanging cages equipped with infrared emitter-detector photocells [32]. Experimental anxiety was measured on the EPM as previously described [33]. The EPM was located in a sound-insulated room with 1.5-2.0 lux of illumination for the open arms and $<1$ lux for the enclosed arms.

\section{General experimental protocol}

All rats (except subjects designated for delay-discounting tests, below) were trained to self-administer oral ethyl alcohol $(10 \% \mathrm{w} / \mathrm{v})$ or intravenous cocaine $(0.25 \mathrm{mg} /$ infusion) on a fixed ratio 1 (FR 1 ) schedule in daily $30 \mathrm{~min}$ (alcohol) or $2 \mathrm{~h}$ (cocaine) sessions using established procedures adapted from [31, 35]. In preparation for environmentally induced reinstatement testing, alcohol or cocaine availability was conditioned to a compound contextual stimulus, consisting of an olfactory component (banana extract; McCormick, Hunt Valley, MD) generated by depositing five drops of extract into the chamber's bedding) plus an auditory (70 dB white noise) component. [As a technical note, the environmentally induced reinstatement procedure was identical to the discriminative stimulus $\left(S_{D}-S^{+} / S^{-}\right)$model we have used in the past to study cocaine-seeking [35-40] and alcohol-seeking [31, 41-45] behaviors. Although, historically, we termed this methodology a "discriminative stimulus" procedure (i.e., before the concept of "context" received attention in the addiction field), the $S_{D}$ stimulus context serves as an occasion setter like the $A / B$ stimulus environments in context studies. As well, operationally, the $S_{D}$ procedure is identical to $A B A$ renewal/context-induced procedures [46], with only technical differences that have little bearing on the operational definition of reinstatement as behavior induced by context. Therefore, in the interest of terminological consistency across the literature, we define the behavioral effects of the $S_{D}$ procedure as context-induced]. Daily training under these conditions continued for a total of 10 sessions. During this phase, rats designated for stress-induced reinstatement continued drug self-administration without contextual conditioning. Drugreinforced responding then was extinguished in daily 30-min sessions in the absence of the contextual stimulus until rats reached a criterion of $\leqq 5$ responses over three sessions. Following extinction, rats entered a 4-day VEH gel treatment phase (PreTx:VEH) for habituation and recording of baseline reinstatement performance induced by re-exposure to the contextual stimulus or the pharmacological stressor yohimbine. Rats then were matched based on their baseline reinstatement performance and divided into a CBD treatment and CBD vehicle control group. This matched-pair assignment assured an identical distribution of higher, average, and lower reinstatement responders in both groups. Rats in the respective groups then received either vehicle gel or CBD (in a gel volume of $\approx 640 \mu \mathrm{l} / \mathrm{kg}$ corresponding to $\approx 15 \mathrm{mg} / \mathrm{kg}(\mathrm{CBD}$ ) at $24 \mathrm{~h}$ intervals over a 7-day treatment phase $(T x: C B D / V E H)$. Following application, rats were single-housed for $4 \mathrm{~h}$ before testing or returned to group housing on non-test days. Effects of CBD on reinstatement of drug seeking were established in 30-min session (in separate groups for the context and stress manipulations) on treatment days 1, 4, and 7 and on locomotor activity on day 6 . Testing then continued without further $\mathrm{CBD}$ or vehicle treatment at early (day 3), intermediate (days 18, 48) and, in the alcohol group, late (day 138) post-treatment (PostTx) stages. Additionally, one test of experimental anxiety (EPM) was conducted on PostTx day 2. In separate groups of drug-naive rats, CBD was probed for nonspecific amotivational effects (i.e., context and stress-induced reinstatement motivated by a palatable natural reinforcer). The treatment design and sequence of behavioral tests are illustrated in Fig. 1 (see supplementary online material for additional procedural details).

\section{Reinstatement-drugs of abuse}

Context-induced and stress-induced reinstatement tests were conducted using within-subject designs. For context-induced reinstatement, the drug-associated compound stimulus was re-introduced $30 \mathrm{~s}$ before onset of testing (Fig. 1), and remained present until session termination. Stress-induced reinstatement, studied in a separate group of rats, was induced by yohimbine $(1.25 \mathrm{mg} / \mathrm{kg} ; \mathrm{IP})$, administered $30 \mathrm{~min}$ before session onset. To establish the generality of CBD effects on stress-induced drug seeking, a separate group of rats with an alcohol self-administration and CBD treatment history identical to that of the yohimbine group was tested for reinstatement induced by $15 \mathrm{~min}$ of variable intermittent electric footshock (current intensity $0.5 \mathrm{~mA}$, as previously described [45] on treatment day 7). 


\begin{tabular}{|c|c|c|c|c|c|c|c|c|c|c|c|c|c|c|c|c|c|c|c|c|c|}
\hline \multirow{3}{*}{\begin{tabular}{|l} 
Treatment \& \\
Test Phases \\
Days
\end{tabular}} & \multirow{2}{*}{\multicolumn{4}{|c|}{\begin{tabular}{c|}
-4 Days $\rightarrow$ \\
Vehicle \\
$\left(\right.$ Pre $\left.T_{\mathrm{X}}: \mathrm{VEH}\right)$
\end{tabular}}} & \multirow{2}{*}{\multicolumn{8}{|c|}{$\begin{array}{c}\longrightarrow \\
\text { Treatment } \\
\left(\mathrm{T}_{\mathrm{X}}: \text { CBDNEH }\right)\end{array}$}} & \multicolumn{9}{|c|}{$\longleftrightarrow 138$ Days $(\sim 5$ months $) \longrightarrow$} \\
\hline & & & & & & & & & & & & & & & & & $\begin{array}{l}\text { oTres } \\
\text { (Pos }\end{array}$ & $\begin{array}{l}\text { tment } \\
\left.t T_{x}\right)\end{array}$ & & & \\
\hline & 1 & 2 & 3 & 4 & 1 & 2 & 3 & 4 & 5 & & 6 & 7 & 1 & 2 & 3 & 14 days & 18 & 30 days & 48 & 90 days & 138 \\
\hline Reinstatement: Contextual & & & 8 & & 8 & & & 8 & & & & O̊ & & & 8 & & 8 & & 8 & & - \\
\hline Experimental Anxiety & & & & & & & & & & & & & & 8 & & & & & & & \\
\hline Locomotor Activity & & & & & & & & & & & 5 & & & & & & & & & & \\
\hline Reinstatement: Stress & & & 8 & & 8 & & & 8 & & & & 8 & & & 叫 & & 8 & & 8 & & • \\
\hline CBD Brain/Plasma Levels & & & & & & & & & & & & $\hat{\Delta}$ & & & $\Delta$ & & $\mathbf{A}$ & & $\Delta$ & & $\boldsymbol{\Delta}$ \\
\hline
\end{tabular}

Fig. 1 Experimental design. Effects of CBD were established on recovery of extinguished drug seeking on treatment days 1, 4, and 7. Testing then continued without further CBD or vehicle (VEH) treatment at early (day 3), intermediate (days 18, 48), and late (day 138) post-treatment stages. Additionally, one test of experimental anxiety (EPM) was conducted on post-treatment day 2. The diagram illustrates the design and sequence of CBD vs vehicle (VEH) treatments and behavioral tests across experimental phases. PreTx:VEH daily VEH gel.T:CBD/VEHdaily CBD or VEH gel. To evaluate the drug specificity of its effects, CBD was probed at some time points for interference with context and stress-induced reinstatement motivated by a sweet solution in separate groups of drug-naive rats. PostTx no treatment. Symbols denote ethanol (O), cocaine $(O)$, or sweet solution $(\square)$ self-administration history, and sampling days for plasma $(\Delta)$ and brain $(\boldsymbol{\Lambda})$ CBD levels

Reinstatement-palatable natural reinforcer (sweet solution) To establish that reduction of drug seeking by CBD is not the result of general "amotivational" actions, we examined CBD for effects on reinstatement motivated by a sweet solution [(SSC) $3 \%$ glucose, $0.125 \%$ saccharin]. Drug-naive rats with a history of SSC self-administration and subjected to the 7-day CBD treatment regimen were tested for context-induced reinstatement of SSC seeking induced by a SSC stimulus context on treatment day 1 , and for yohimbine stress-induced reinstatement on PostTx days 3 and 18.

Locomotor activity

To examine effects of CBD on spontaneous locomotor activity, rats of the alcohol and cocaine contextual reinstatement groups were placed into locomotor activity cages $4 \mathrm{~h}$ after CBD application on treatment day 6.

\section{Experimental anxiety}

Anti-anxiety effects of CBD were evaluated on the EPM test as previously described [47]. On PostTx day 2, rats of the context reinstatement group were habituated for $2 \mathrm{~h}$ to the EPM procedure in the presence of white noise $(70 \mathrm{~dB})$ and then placed individually onto the center of the EPM facing a closed arm, with white noise $(70 \mathrm{~dB})$ present. During 5 -min tests, behavior was recorded by video camera and scored blind for time spent in the open and closed arms. EPM performance was expressed as $\%$ time in open arms $/(\%$ time in open arms $+\%$ time in closed arms). To determine whether the $15 \mathrm{mg} / \mathrm{kg}$ dose used for CBD effects on experimental anxiety lies on the ascending limb of a possibly $U$ shaped CBD dose-response function, a second EPM study was conducted in a different group of drug-naive rats comparing two doses of CBD (15 and $30 \mathrm{mg} / \mathrm{kg}$ ) vs. vehicle.

\section{Impulsive choice-delay discounting}

CBD effects on impulsive behavior in rats with a history of alcohol dependence were studied using the "delay discounting" model in which impulsivity is defined as the selection of a small immediate over a larger delayed food reward (impulsive choice). Rats, maintained at $85-90 \%$ of free-feeding weight to ensure reliable motivation to work for food pellet reinforcers, were trained on a delayed reward task using established procedures (adapted from [34]). Rats were initially trained under a forced-choice contingency to obtain immediate small (1 pellet) and delayed large (4 pellets) reward by nose-poke responses. Subsequently, free-choice trials began in which nose pokes in one hole produced immediate small reward and responses in the other hole produced large delayed reward, allowing for choice of the preferred reward. Failure to make a response within $10 \mathrm{~s}$ was counted as an omission and initiated a new intertrial interval. The respective nose-poke hole and food magazine position associated with the small and large reward was the same for individual rats, but counterbalanced across rats. Delays for the large reward increased progressively $(0$, $5,10,20$, and 40 s) within each session per block of 12 trials. Daily trials continued until stable responding was established across a block of 5 sessions. Rats then were subjected to a 7-day dependence-inducing intragastric alcohol intoxication (vs. vehicle) procedure as previously described [48] during which they were treated at $24 \mathrm{~h}$ intervals with CBD $(\approx 15.0 \mathrm{mg} / \mathrm{kg})$ or vehicle gel. Following 5 days of recovery, testing resumed for 10 sessions to record performance in the delayed reward task. Data were expressed as the number of choices of large reward/(number choices large + small reward) $\times 100$.

Plasma and brain CBD levels

For determination of plasma $C B D$, rats received two $C B D$ doses (15 mg/kg or $30 \mathrm{mg} / \mathrm{kg}$ ). Blood samples were obtained on $T x$ day 7, $4 \mathrm{~h}$ after CBD application, and three PostTx time points corresponding those of behavioral testing (Fig. 1). Blood (100 $\mu \mathrm{l})$ was collected by the tail bleed method. Plasma was separated by centrifugation and stored at $-80^{\circ} \mathrm{C}$. Samples were analyzed by electrospray LC-MS as previously described [26, 30]. The limit of detection (LOD) was $1 \mathrm{ng} / \mathrm{ml}$. For measurement of brain CBD levels, rats received the $15 \mathrm{mg} / \mathrm{kg}$ CBD dose used in the behavioral studies. Brain tissue was obtained at the same time points used for plasma sampling (Fig. 1). CBD was extracted from brain tissue by homogenization in chloroform/methanol [49] containing $100 \mathrm{ng} /$ $\mathrm{ml}$ of $\mathrm{CBD}-\mathrm{d}_{3}$ as internal standard (8:3:1) followed by centrifugation, decanting of the lower supernatant phase, evaporation and reconstitution in acetonitrile for analysis. Samples were analyzed for CBD (and CBD- $\mathrm{d}_{3}$ ) by electrospray LC-MS. The LOD was $0.2 \mathrm{ng} / \mathrm{ml}$.

\section{Data analysis}

Differences between CBD and VEH effects on reinstatement induced stimuli conditioned to alcohol, cocaine, natural reward, and yohimbine stress (including only the Tx and PostTx phases) were separately analyzed by mixed-factorial analyses of variance (ANOVA). Following confirmation of significant main effects in the overall ANOVA, differences between group means across time were verified by simple effects ANOVAs. Differences between extinction and baseline reinstatement, Tx, or PostTx days were analyzed by Student's $t$-tests. CBD vs VEH effects on footshockinduced reinstatement were analyzed by Student's $t$-tests (2tailed). CBD vs VEH effects on experimental anxiety in the EPM test 
were separately analyzed for open arm time and crossings by Student's $t$-tests. Dose-dependent effects of CBD vs VEH on experimental anxiety in drug-naive rats were analyzed by one-way ANOVA followed by Tukey's post hoc tests. Effects of CBD vs VEH on locomotor activity were analyzed separately for the alcohol and cocaine groups by Student's $t$-test. Effects of CBD vs VEH on the development of impulsive choice were analyzed by mixedfactorial ANOVA, followed by Tukey's post hoc tests to ascertain differences among individual means. Plasma CBD levels produced by the two CBD doses and brain CBD levels in CBD-treated vs drug-naive controls were analyzed by mixed-factorial ANOVA, followed by simple effects ANOVAs to confirm differences among group means across time.

\section{RESULTS}

CBD attenuates drug seeking with effects that far outlast treatment

Given the reported interactions of CBD with brain circuitry that mediates drug-seeking behavior, our initial objective was to determine whether CBD reduces drug seeking in animal models of relapse utilizing exposure to drug-associated environmental stimulus contexts and stress to reinstate previously extinguished drug-seeking behavior (reinstatement). In doing so, we sought to also establish (a) whether CBD modifies drug seeking with acute administration or requires multiple application, (b) whether tolerance develops to the effects of CBD with repeated treatment, and (c) whether effects of CBD on drug-seeking outlast termination of the CBD treatment (for experimental design and sequence of procedures, see Fig. 1).

\section{Reinstatement-alcohol}

Drug seeking (reinstatement) induced by the stimulus context previously associated with alcohol availability was significant $(p<$ 0.001 ) in a baseline reinstatement test during the VEH gel pretreatment phase (Fig. 2a left panel: Pre-Tx/VEH) before pairmatched assignment to continued CBD vs VEH treatment $(N=12$ / group; There were no statistical differences in responding between animals assigned to these groups during the final day of alcohol self-administration (data not shown). Reinstatement in the VEH group remained unaltered throughout all subsequent tests. Acute CBD on treatment (day 1 ) reduced reinstatement $(p<$ 0.05) compared to VEH, and CBD continued to attenuate reinstatement with repeated application over the treatment phase $(p<0.05, p<0.01$; Fig. 2a center panel: Tx:CBD/NEH). Reinstatement remained attenuated ( $p<0.05, p<0.01$; Fig. 2a right panel) across the entire 138-day post-treatment (PostTx) phase (simple effects ANOVAs following main effect of drug treatment in mixedfactorial ANOVA: $\mathrm{F}_{1,22}=11.31, p<0.01$ ).

Stress-induced alcohol seeking (induced by acute administration of the pharmacological stressor yohimbine) also increased significantly over extinction performance $(p<0.05)$ during the baseline reinstatement test (Fig. 2b left panel: PreTX:VEH) before matched-pair assignment to treatment with CBD vs VEH $(N=12 /$ group. There had been no statistical differences in responding between rats assigned to these groups during the final alcohol self-administration day. (data not shown). Effects of yohimbine alone on reinstatement increased with repeated administration across experimental phases $\left(\mathrm{F}_{7,161}=6.95, p<0.01\right)$. CBD significantly reduced the effects of yohimbine following acute application ( $p<0.05$; Fig. $2 \mathrm{~b}$ center panel: Tx:CBD/NEH, day 1$)$, remained effective with repeated administration $(p<0.05)$, and the attenuation of reinstatement outlasted CBD treatment across the 138-day PostTx phase $(p<0.05$; Fig. $2 \mathrm{~b}$ right panel; simple effects following main effect of drug treatment in mixed-factorial ANOVA: $F_{1,22}=$ $5.93, p<0.05)$. Yohimbine, a noradrenergic $\mathrm{a}_{2}$ receptor antagonist, has found application as an alternative to footshock in animal models of stress-induced relapse [50], but it has also been
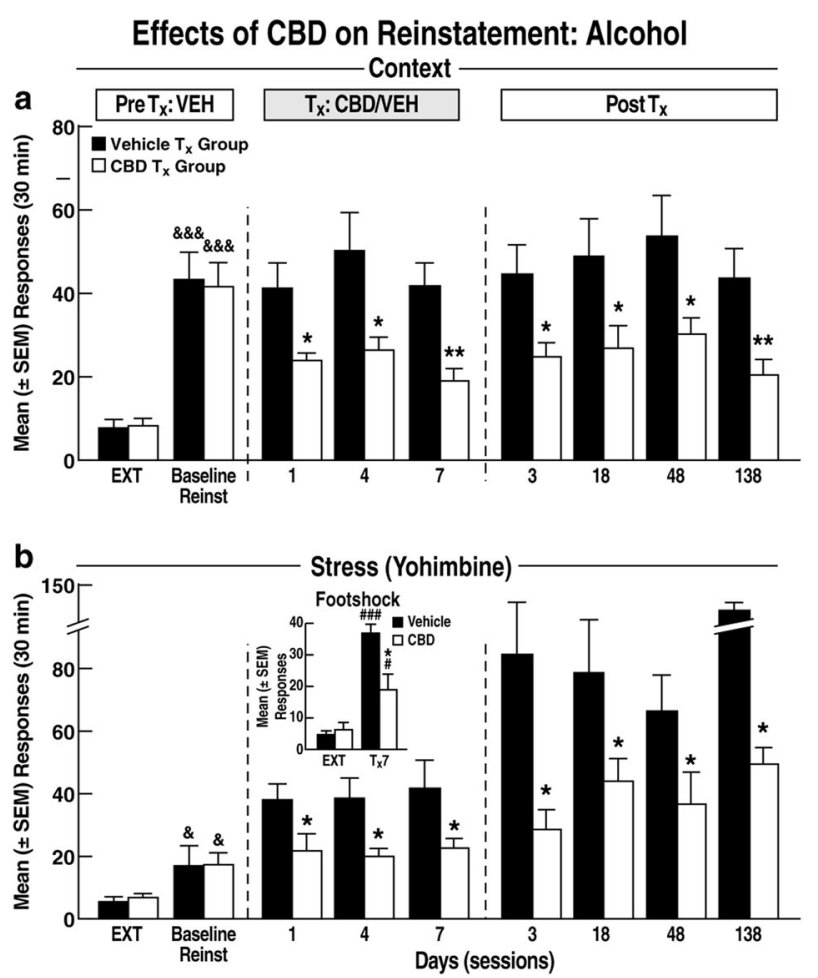

Fig. 2 Reinstatement of ethanol seeking. a Contextual reinstatement. PreTx:VEH: extinction (EXT) and "Baseline Reinstatement" performance during the VEH pretreatment phase. Note: Data represent behavior in rats assigned to CBD or VEH treatment $(N=$ 12 /group) as matched pairs after completion of the baseline reinstatement test. Tx:CBD/VEH: reinstatement during $C B D$ or $V E H$ treatment. PostTx: reinstatement after termination of CBD treatment. ${ }^{\&} \& \& p<0.01$ vs extinction (EXT); ${ }^{*} p<0.05,{ }^{* *} p<0.01$ vs VEH. b Stressinduced reinstatement. PreTX:VEH: yohimbine-induced "baseline" reinstatement. Tx:CBD/VEH: reinstatement during $C B D$ or $V E H$ treatment $(N=12 /$ group). PostTx: Reinstatement across the CBDfree test phase. ${ }^{\&} p<0.05$ vs EXT; ${ }^{*} p<0.05$ vs VEH. Inset: Footshockinduced reinstatement. ${ }^{*} p<0.05$ vs VEH; ${ }^{\#} p<0.05$, \#\#\# $p<0.001$ vs EXT $(N=11 /$ group). Note: Ordinate scales are standardized across drugs for context and stress-induced reinstatement respectively in Figs. 2 and 3, but differ within each figure for context and stress effects for the sake of clarity

questioned whether yohimbine effects on drug seeking are related to stress-like actions [51]. To address this issue, effects of $\mathrm{CBD}$ on reinstatement induced by a "traditional" experimental stressor, footshock, were examined in a separate group of rats. Only a single test was conducted because within-subjects designs with repeated footshock tests are not feasible due inconsistent/ variable reinstatement performance associated with such designs. Footshock-induced reinstatement ( $T x$ day 7 ; Fig. $2 b$ inset) after extinction ( $p<0.05$ : CBD vs extinction; $p<0.001$ : VEH vs extinction) was as sensitive to the "anti-reinstatement" actions of CBD as yohimbine-induced behavior, with $a \approx 50 \%$ reduction in alcohol seeking ( $t_{8}=2.78, p<0.05 ; N=5 /$ group).

Reinstatement-cocaine

Here we sought to establish whether the effects of CBD on alcohol seeking extend to other drugs of abuse by replicating the above experiment in rats with a history of intravenous cocaine selfadministration, except that tests following CBD treatment termination were limited to the early (day 3 ), and intermediate (days 18, 48) PostTx stages.

Context-induced cocaine seeking in the baseline reinstatement test during the VEH gel pretreatment phase (Fig. 3a left panel: PreTx:VEH) was significant $(p<0.001)$ before pair-matched 
Effects of CBD on Reinstatement: Cocaine
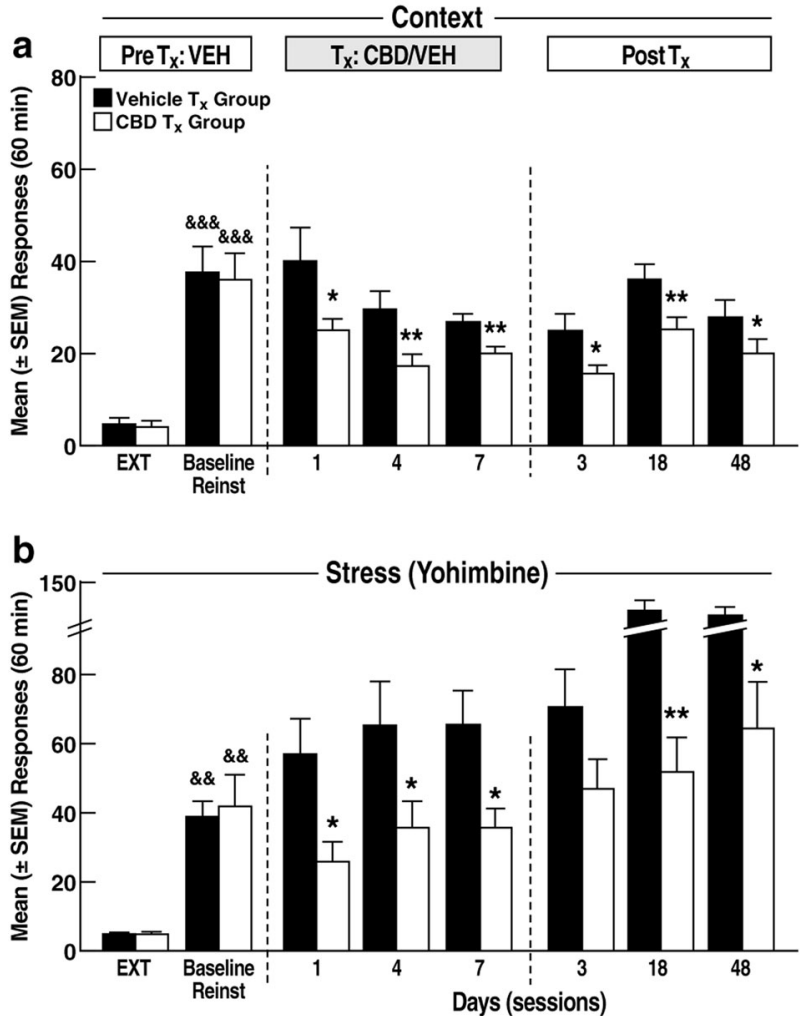

Fig. 3 Reinstatement of cocaine seeking. a Contextual reinstatement $(N=11 /$ group). b Yohimbine-induced reinstatement $(N=12 /$ group). For both contextual and stress-induced reinstatement, the same profile of effects was observed as in rats with an ethanol history across all three experimental phases (Fig. 2). ${ }^{\& \&} p<0.01$ vs EXT; ${ }^{*} p<0.05,{ }^{* *} p<0.01$ vs VEH. Note: EXT and "Baseline Reinstatement" data represent behavior of rats assigned to either CBD or VEH treatment as matched pairs after completion of the baseline reinstatement test assignment to CBD vs. VEH treatment ( $N=11 /$ group). No statistical differences in responding between rats assigned to these groups were found during the last day of cocaine selfadministration (data not shown). We observed the same overall profile of CBD effects as in alcohol-seeking rats, with significant inhibitory effects of $C B D$ on context-induced cocaine seeking during the $T x$ phase $(p<0.05, p<0.01$; Fig. 3a center panel: $T x$ : $(B D / V E H)$, and persistence of these effects throughout the 48-day PostTx phase (Fig. 3a right panel), again at $p<0.05$ and $p<0.01$ levels (simple effects following main effect of drug treatment in mixed-factorial ANOVA: $\mathrm{F}_{1,20}=8.93, p<0.01$ ).

Yohimbine stress-induced reinstatement of cocaine seeking during the VEH baseline test (Fig. 3b left panel: PreTx:VEH) increased significantly over extinction performance $(p<0.01)$ before pair matching for assignment to CBD vs vehicle treatment ( $N=12$ /group). No differences in responding between rats assigned to these groups were found during the last day selfadministration (data not shown). We observed the same profile of yohimbine and CBD effects as in alcohol-seeking rats. Yohimbineinduced reinstatement increased with repeated treatment across experimental phases, presumably reflecting sensitization to the stressor $\left(F_{6,120}=6.96, p<0.01\right)$ and $C B D$ significantly reduced these effects of yohimbine (Fig. $3 \mathrm{~b}$ center and right panels) at each time point throughout the Tx:CBD/VEH $(p<0.05)$ and PostTx $(p<0.05, p<0.01)$ stages (simple effects following main effect of drug treatment in mixed-factorial ANOVA: $\mathrm{F}_{1.19}=11.71, p<001 ; N$ $=12$ /group).

CBD attenuates experimental anxiety in rats with alcohol and cocaine histories

Elevated anxiety following chronic drug use is a risk factor for relapse. We therefore examined whether CBD's anti-anxiety effects $[15,16]$ extend to animals with a history of alcohol or cocaine selfadministration. CBD significantly reduced experimental anxiety, reflected by increased EPM open arm time compared to VEH controls in rats with either alcohol $\left(t_{22}=1.96, p<0.05 ; N=12\right.$ / group) or cocaine $\left(t_{19}=2.76, p<0.05 ; \mathrm{CBD}: N=9\right.$; VEH: $\left.N=12\right)$ histories (Fig. 4a, b). CBD did not alter open arm crossings, a measure of locomotor activity, in either group of rats (alcohol: $t_{22}$ $=0.64$, NS; cocaine: $t_{19}=0.87$, NS; data not shown). The antianxiety effects of CBD showed dose dependence (Fig. 4c) as

\section{Effects of CBD on Experimental Anxiety}
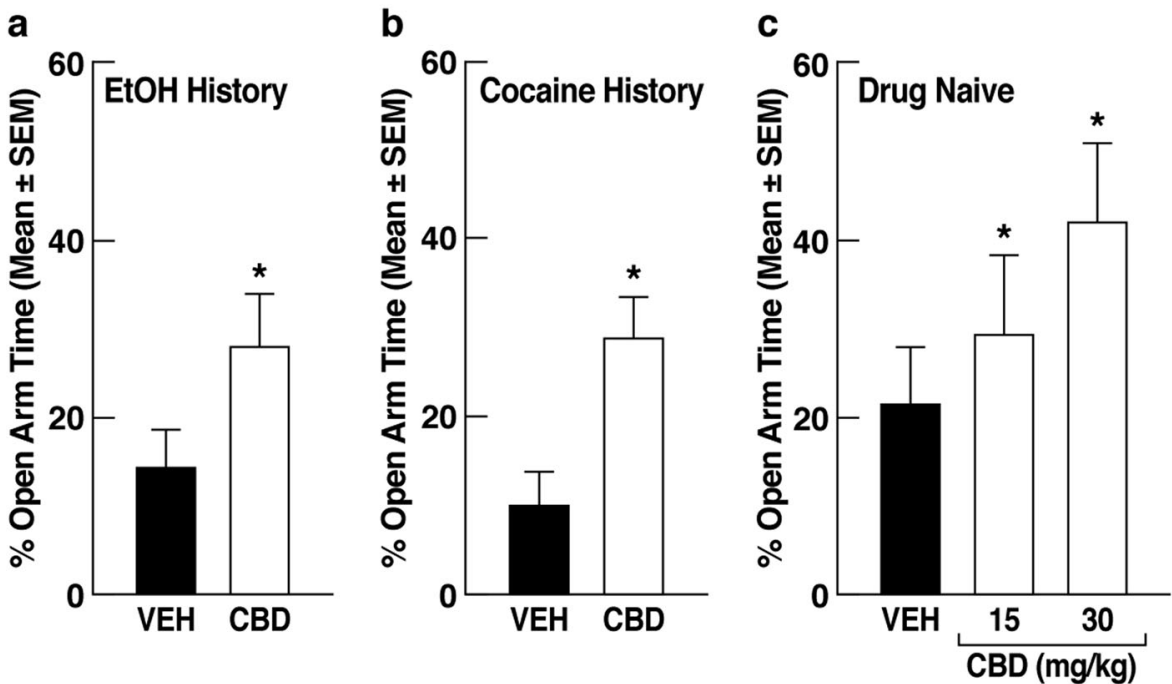

Fig. 4 Effects on experimental anxiety. Effects on experimental (EPM open arm time) in rats with a an alcohol ( $N=12 / g r o u p)$ or $\mathbf{b}$ cocaine (CBD: $N=9$, VEH: $N=12$ ) history. In both drug history groups CBD significantly reduced anxiety-like behavior, reflected by increased EPM open arm time as measured on PostTx day 2. c Dose dependence of the CBD effects on EPM open arm time measured in drug-naive rats on PostTx day 2 ( $N=10 /$ group). ${ }^{*} p<0.05$ vs VEH. 

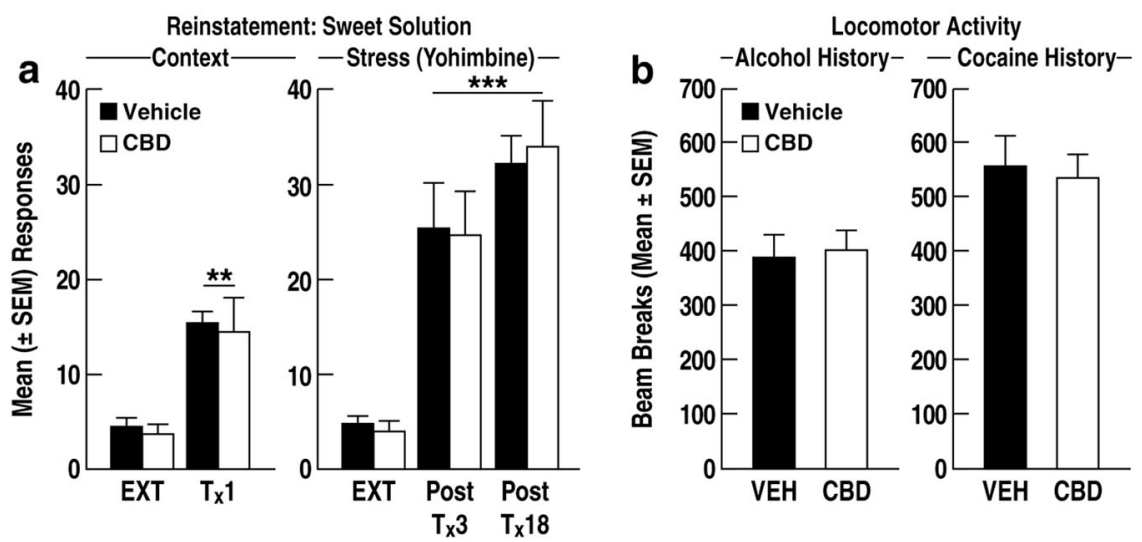

Fig. 5 Tests for nonspecific CBD effects. a Reward seeking motivated by palatable sweet solution. Left panel: Effects of CBD on reinstatement induced by contextual cues conditioned to availability of sweet solution reward ( $N=6 /$ group). Right panel: Effects of CBD on yohimbineinduced reinstatement of sweet solution seeking $(N=6 /$ group). No statistical differences were found between VEH and CBD treatment on contextual or yohimbine-induced behavior. ${ }^{* *} p<0.01,{ }^{* * *} p<0.001$ vs EXT. b Effects of CBD on spontaneous locomotor activity in rats with an alcohol (left panel; $N=12$ /group) or cocaine (right panel; $N=11 /$ group) history

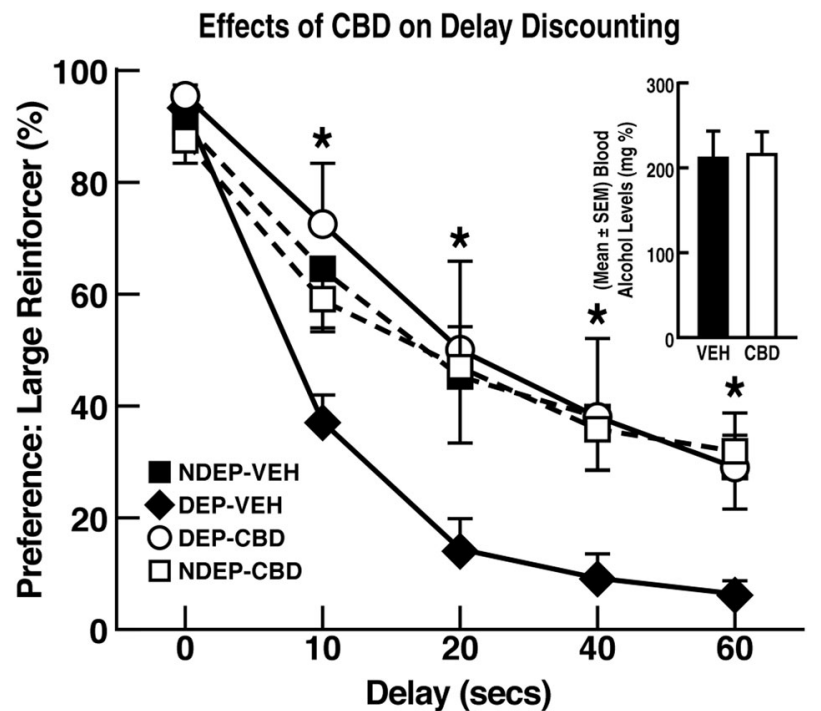

Fig. 6 Preference for delayed large over small immediate reward as a function of delay time. Preference for delayed large reward was significantly lower in rats with an EtOH dependence history (DEPVEH) than nondependent controls (NDEP-VEH) and nondependent CBD-treated (NDEP-CBD) rats. This effect was fully reversed by CBD (DEP-CBD). ${ }^{*} p<0.05$ DEP-VEH $(N=7)$ vs DEP-CBD $(N=6)$, DEP-VEH $(N=7)$, and NDEP-CBD $(N=7)$

measured in separate groups ( $N=10 /$ group) of drug-naive rats $(15 \mathrm{mg} / \mathrm{kg}$ vs VEH: $p<0.05 ; 30 \mathrm{mg} / \mathrm{kg}$ vs VEH: $p<0.001$; Tukey's post hoc tests following ANOVA: $F_{2,27}=10.99, p<0.001$ ).

CBD is devoid of sedative and nonspecific amotivational effects In contrast to its effects on alcohol and cocaine seeking, CBD did not interfere with either context-induced $\left(t_{10}=0.05, N S ; N=6\right.$ / group) or yohimbine stress-induced $\left(\mathrm{F}_{1,10}=0.02, \mathrm{NS} ; N=6 /\right.$ group) reinstatement of reward seeking motivated by a highly palatable glucose-saccharin sweet solution (Fig. 5a) at time points of the Treatment and PostTx phases at which significant effects of CBD on drug seeking had been observed (Figs. 1, 2, 3). As well, extending the finding that CBD did not alter EPM crossings into the closed arms (see supplementary online material, Figure S2), an effect indicative of absence of motor impairment, we observed no impairment in mean $( \pm S E M)$ locomotor activity in CBD-treated rats with either alcohol ( $t_{22}=0.18, N S ; N=12$ /group) or cocaine $\left(t_{20}=\right.$ 0.38 , NS; $N=11 /$ group) histories (Fig. $5 \mathrm{~b}$ ) as measured at a time (Tx:CBD/NEH, day 6; see Fig. 1) when CBD significantly attenuated context and yohimbine stress-induced reinstatement (Figs. 2, 3: TX: $C B D / V E H$, day 7). Consistent with these findings, no significant effects of $C B D$ or yohimbine were found on inactive lever responses during reinstatement tests (see supplementary online material Fig. 2,3 for inactive lever responses in the yohimbine groups).

CBD reverses impulsive behavior in rats with an alcohol dependence history

Alcohol (ab)use is linked to impulsivity in man $[52,53]$ and impaired impulse control is a risk factor for relapse [54]. In animals, impulsive choice (i.e., inability to choose large delayed reward over small immediate reward) is predictive of high-alcohol intake and "loss of control" drinking [55-57]. Using this model, we show that rats with a dependence-inducing alcohol intoxication history display significantly reduced preference for large delayed reward (i.e., impulsive choice) compared to alcohol vehicle-treated rats ( $p$ $<0.05)$. CBD treatment during the alcohol intoxication period prevented development of impulsive choice $(p<0.05$; Tukey post hoc tests following ANOVA: $\mathrm{F}_{3,23}=6.45, p<0.01 ; \mathrm{N}=6-7 /$ group; Fig. 6). CBD did not alter choice behavior in rats without an alcohol dependence history. Blood alcohol levels in vehicle- and CBDtreated rats, measured on the final day of alcohol intoxication, were identical (mean \pm SEM: $C B D=214.4 \pm 31.0, \mathrm{VEH}=211.1 \pm$ 31.6; Fig. 6 inset).

\section{CBD plasma and brain levels}

CBD is highly lipophilic such that it could not be ruled out that pharmacologically active concentrations remain in plasma and brain, which may partially or fully be responsible for the drug's lasting post-treatment effects. We therefore measured plasma and brain CBD levels in separate groups of rats throughout the PostTx phase in comparison with the with the late CBD treatment phase. Measurement of plasma levels also served the purpose of ascertaining that the CBD formulation produced dosedependent CBD elevations in plasma. Significant and dosedependent CBD levels were detected in plasma as measured on $T x$ day 7 ( $p<0.001$ vs $15 \mathrm{mg}$ ). Dose-dependent CBD levels were still detectable on PostTx day 3 ( $p<0.05$ vs $15 \mathrm{mg}$ ) but were minimal at the $15 \mathrm{mg} / \mathrm{kg}$ CBD dose used for the reinstatement 


\section{CBD Plasma and Brain Concentrations}
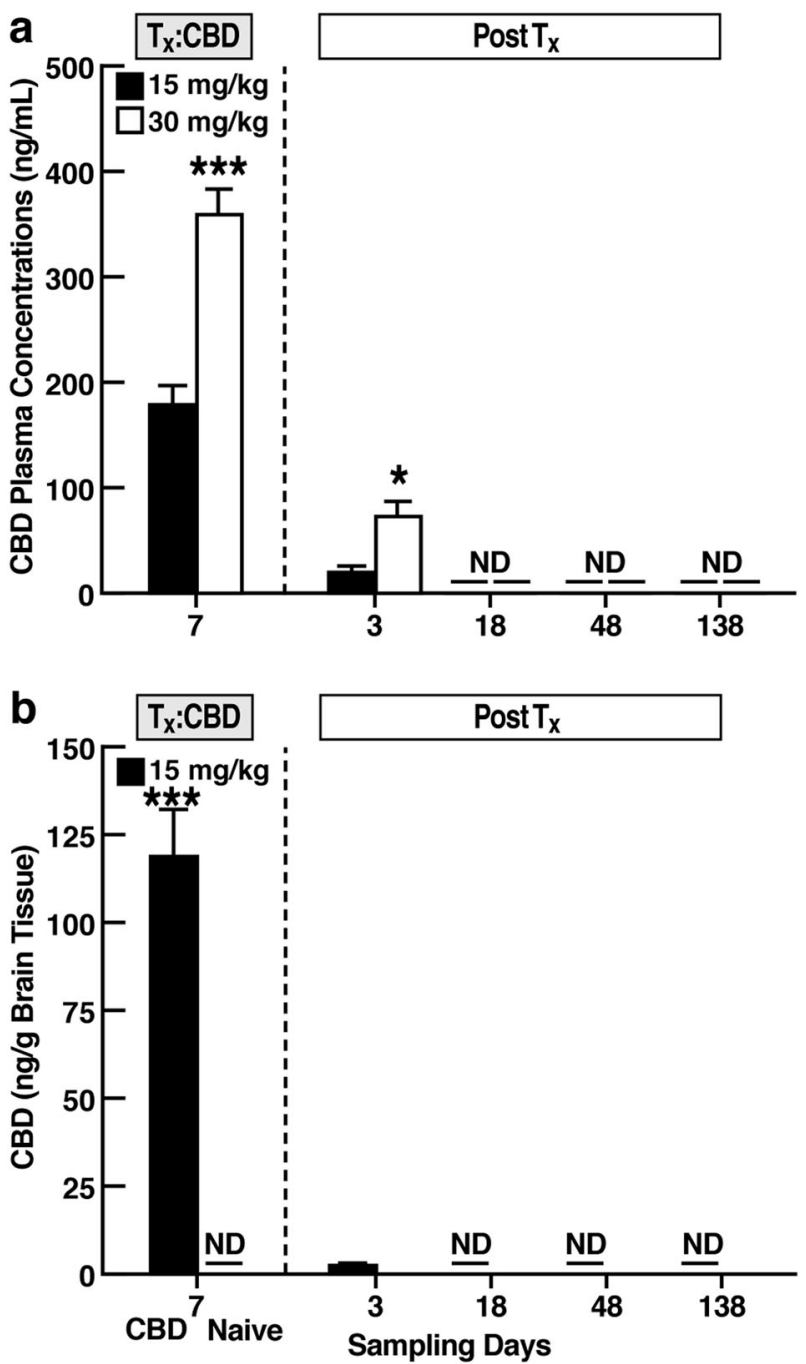

Fig. 7 Plasma and brain CBD concentrations. a Plasma levels differed significantly by dose on $T x$ day 7 and PostTx day $3 .{ }^{*} p<0.05$, ${ }^{* *} p<0.01 ;{ }^{* * *} p<0.001$ vs $15 \mathrm{mg} / \mathrm{kg}$. (ND not detectable; in Fig. $7 \mathrm{~b}$ not collected). b Brain CBD concentrations in CBD-treated (left bars: $15 \mathrm{mg} / \mathrm{kg}$ ) rats differed from untreated controls (right bars: "ND") on $T x$ day 7 and PostTx day $3(N=10 /$ dose). Brain CBD in untreated controls was below detection limits, as was $C B D$ in $C B D$-treated rats on PostTx days $18-138(N=4 /$ group $)$

studies (Fig. 7a; simple effects following ANOVA: $\mathrm{F}_{1,18}=25.88, p<$ $0.001 ; N=10 /$ dose). $C B D$ was undetectable (i.e., within instrument error) at later PostTx stages. CBD levels in brain were measured in rats treated with a single $15 \mathrm{mg} / \mathrm{kg} C B D$ dose vs drug-naive controls. Corresponding to the CBD plasma levels at the $15 \mathrm{mg} / \mathrm{kg}$ dose, CBD was present in brain at high levels on treatment day 7 $(p<0.001$; Fig. 7b) and was still above detection limits on PostTx day 3 (although not statistically different from drug naive controls), but not the remaining PostTx times (Newman-Keuls following ANOVA: $\mathrm{F}_{5,18}=106.8, p<0.0001 ; N=4$ /group).

\section{DISCUSSION}

The results document two unique "therapeutic" dimensions of CBD. First, $C B D$ exerted beneficial effects relevant for several relapse-promoting conditions including sensitivity to drug-related contexts and stress, anxiety, and impaired impulse control. These observations are consistent with the hypothesis and provide proof of principle supporting the potential of CBD to concurrently ameliorate multiple vulnerability states that underlie relapse risk. Second, CBD produced unexpected long-lasting "therapeutic" effects following only brief treatment in the two reinstatement models of relapse. Further adding to the treatment promise of $C B D$, the efficacy of the cannabinoid to reduce reinstatement in rats with both alcohol and cocaine-and, as previously reported, heroin [11] -histories predicts therapeutic potential for addiction treatment across several classes of abused drugs.

Effects of CBD on relapse-like behavior

Vulnerability to relapse is a chronic condition in substance use disorders $[13,14]$. We therefore conducted the tests of CBD effects on context- and stress-induced drug seeking "longitudinally" to permit evaluation across repeated "relapse" challenges. The alcohol and cocaine stimulus contexts produced perseverating reinstatement without decrease in magnitude over time (see also [38]). Yohimbine-induced reinstatement increased over time in both alcohol-seeking and cocaine-seeking rats, presumably due to sensitization. Compared to vehicle treatment, CBD reduced both context and yohimbine-induced drug seeking when applied acutely (day 1), and repeated treatment did not result in tolerance to these effects. Strikingly, both context and yohimbine-induced drug seeking remained significantly reduced long after termination of CBD treatment; in the case of alcohol as late as $\sim 5$ months following treatment discontinuation. The attenuation of drug seeking cannot be attributed to nonspecific effects. Not only did CBD not interfere with reward seeking motivated by a highly palatable sweet solution at the time points and under the conditions probed, but also failed to alter locomotor behavior either in the activity test or as measured by EPM arm crossings. Concerning the attenuation of stress-associated drug seeking, CBD reduced not only the effects of yohimbine but also footshock stress. The latter finding is limited to a single test in rats with an alcohol history, but supports the generality of CBD's beneficial effects in reducing the consequences of stress challenges on alcohol seeking, an effect that one may hypothesize extends to cocaine seeking. Yohimbine has found growing application as a stressor in studies of drug seeking [58] but, in contrast to footshock [59], yohimbine's effects in reinstatement studies may not be related to commonly assumed stress-like effects [51]. On the other hand, the validity of reinstatement induced by footshock stress has been questioned because footshock does not parallel the stressors encountered by humans [60]. Nonetheless, the efficacy of CBD to attenuate the effects of two distinct presumptive stress manipulations in animals has translational implications concerning likely clinical potential of CBD for reducing the impact of stress on drug craving and relapse. In this regard, the results also suggest that $C B D$ attenuates sensitization to stress as a vulnerability factor for relapse as implied by the reduction of sensitized drug seeking following repeated yohimbine treatment.

The mechanisms underlying the unabated reduction of relapselike behavior by $C B D$ months after treatment termination are presently elusive. A non-mechanistic possible explanation is disruption of contextual drug memory reconsolidation as recently reported in a conditioned place preference model [61]. However, such effects would not explain the reduction in contextual drug seeking during the first reinstatement test (i.e., before disruption of memory reconsolidation by CBD had an opportunity to occur) or the lack of further reduction in drug seeking during subsequent tests (i.e., when the consequences of memory disruption following the first test should have taken effect). Disruption of memory reconsolidation also would not account for the persistent reduction of stress-induced reinstatement. A pharmacokinetic explanation that, due to CBD's high lipophilicity, pharmacologically active concentrations remain in brain and mediate the drug's 
lasting post-treatment effects on both context and stress-induced drug seeking (albeit by unknown mechanisms) was not supported by the data. CBD brain and plasma levels were still detectable on post-treatment day 3 and reflect a skin reservoir effect as we previously reported [30]. This effect unlikely accounts for the reduced reinstatement on this day considering the low brain and plasma levels at the $15 \mathrm{mg} / \mathrm{kg}$ dose used for the behavioral studies and the continued reduction of drug seeking at later posttreatment stages when plasma and brain CBD levels were no longer detectable. Nonetheless, the data obtained on the final treatment day verify that the CBD formulation produced dosedependent CBD plasma levels and significant brain concentrations. Because CBD's effects far outlasted treatment, we focused on the detection of residual brain/plasma CBD during the posttreatment phase in comparison with the late treatment phase. Therefore, it is not clear at present whether plasma and brain levels on treatment day 7 represent levels that accumulate over time or are identical to levels that would be produced by acute treatment.

\section{Anti-anxiety effects}

CBD produced anti-anxiety effects identical in magnitude in rats with alcohol and cocaine histories. This finding parallels evidence of anxiolytic effects by CBD in animals $[15,16]$ and man $[62,63]$. Moreover, consistent with the dose dependence of CBD plasma concentrations, CBD produced dose-dependent anti-anxiety effects in drug-naive rats (Fig. 4c). The EPM tests were conducted 2 days following treatment termination when residual CBD brain concentrations were presumably higher than those detected on post-treatment day 3. It is therefore unclear whether CBD's antianxiety effects in the EPM test are explained by residual CBD brain concentrations or post-treatment effects as possibly suggested by findings of CBD post-treatment effects on fear memory reconsolidation [64]. Despite the preponderance of evidence supporting anxiolytic actions of CBD, these effects may not be universal. Orally administered CBD did not dampen responses to negative emotional stimuli in man [65] and a 14-day intraperitoneal regimen exacerbated the conditioned emotional response in rats [66]. It will therefore be important to more precisely establish the nature of CBD's anti-anxiety profile in the future.

Tentative modes of action

CBD is thought to interact with a vast set of cellular and molecular targets [67]. However, understanding of the mechanisms mediating specific behavioral effects of CBD is highly limited. Similarly, our results do not provide insight into mechanisms for either the acute or lasting post-treatment effects of CBD. It is likely, although speculative, that several among the plethora of CBD's known and presumptive pharmacological actions contributed to the findings. CBD interacts with the endocannabinoid system both as a weak $\mathrm{CB}_{1}$ agonist and by increasing the availability of the endocannabinoid anandamide [67]. The endocannabinoid system participates in neural signaling relevant for perseverating drug seeking [68] as well as behavioral responses to anxiety and stress [69-71]. Therefore, modification of endocannabinoid transmission and possibly long-lasting consequences of this effect provide a presumptive mechanism for CBD's reduction of drug seeking and experimental anxiety. CBD also interacts with neural signaling regulating motivation and reinforcement beyond the endocannabinoid system. Here, particularly allosteric modulation of $\mu$-opioid and $\partial$-opioid receptors [72] and modification of glutamatergic transmission [11, 73] provide a possible mechanism for CBD's "anti-relapse" effects. As well, evidence that CBD has $5-\mathrm{HT}_{1 \mathrm{~A}}$ receptor agonist actions [74] and that $5-\mathrm{HT}_{1 \mathrm{~A}}$ antagonists block the anxiolytic and anti-stress effects of $\mathrm{CBD}[15,75-78]$ implicates $5-\mathrm{HT}_{1 \mathrm{~A}}$ receptors as a target through which $\mathrm{CBD}$ produced its antianxiety actions and amelioration of stress-induced reinstatement. Perhaps most importantly, recent findings implicate neurogenesis in the inhibition of drug seeking and relapse [79]. Therefore, the proneurogenic actions of CBD $[80,81]$ may represent a mechanism to explain the long-lasting attenuation of drug seeking after only brief CBD treatment. Proneurogenic effects have also been implicated in the anti-anxiety effects of CBD [17, 81] and, therefore, may represent a major mode of action by which CBD produces its diverse therapeutic effects.

\section{CBD effects on impulsive behavior}

Consistent with literature linking high-alcohol consumption with the inability to choose large delayed rewards over smaller immediate rewards in animals $[82,83]$, our rats with an alcohol dependence history showed significantly reduced preference for large delayed reward (i.e., impulsive choice). Daily CBD treatment during the alcohol intoxication period prevented the development of this high impulsivity profile. Blood alcohol levels in CBDand $\mathrm{VEH}$-treated rats were identical, ruling out $\mathrm{CBD}$-alcohol interactions (e.g., accelerated alcohol metabolism or clearance) in the prevention of alcohol-induced impulsive choice. The mechanisms underlying the amelioration of impulsive behavior by CBD presumably differ from those mediating its effects on drug seeking and anxiety. A link exists between loss of impulse control and alcohol-induced neuropathology [84]. CBD exerts neuroprotective effects [85] and we have previously reported that $C B D$ attenuates neurodegeneration induced by repeated alcohol intoxication in models similar to that employed here [26]. Dependence-inducing alcohol intoxication produces not only neurodegeneration but also decreases survival and proliferation of nascent neural progenitor cells [86]. CBD facilitates neurogenesis $[17,80,81,87]$ and can reverse cognitive impairment produced by neurodegeneration [88]. CBD may, therefore, not only be protective for alcohol-induced neurodegenerative deficits but also have potential for restoring cognitive function, including deficient impulse control, by promoting neurogenesis. Our efforts focused on the prevention of alcohol-induced impulsivity. These protective effects are clinically relevant for limiting further impairment in impulse control by continued intoxication in alcoholic subjects. It will be important to establish in the future whether $C B D$ reverses impulse control deficits once induced, a possibility implied by the proneurogenic actions of CBD.

In summary, the results provide proof of principle supporting potential of CBD for relapse prevention along two dimensions : beneficial actions across several vulnerability states, and longlasting effects with only brief treatment. To further substantiate this putative large-spectrum treatment potential it will be essential to extend the characterization of CBD's "therapeutic" profile in the future. This includes understanding of the post-treatment persistence of CBD's anti-anxiety effects and its efficacy to reduce anxiety in subjects with a history of more excessive, long-term drug use than modeled here. It will be important also to determine the treatment frequency, duration, and doses at which CBD is most efficacious in exerting both its acute and posttreatment "therapeutic" actions. While these issues and the mechanistic basis of CBD's effects require clarification in the future, the results have significant implications concerning CBD's potential in relapse prevention. Drug addicts enter relapse vulnerability states for multiple reasons. Therefore, effects such as these observed with CBD that concurrently ameliorate several of these are likely to be more effective in preventing relapse than treatments targeting only a single state. As well, the sustained post-treatment attenuation of drug seeking implies that CBD exerts enduring rather than transient ameliorative effects. Identification of the underlying mechanisms may lead to treatments with long-term benefits as well as improved understanding of neuroplasticity responsible for chronic susceptibility to relapse. Insight into the mechanisms by which CBD exerts its multiple beneficial effects in future research may advance and open new vistas for the pharmacotherapeutic prevention of 
relapse to drug use. Finally, the results inform the present medical marijuana debate by confirming that non-psychoactive, nonaddictive constituents of Cannabis sativa such as CBD may be highly effective and readily amenable for development as therapeutics. CBD has found application for the treatment of epilepsy and neuropathic symptoms associated with multiple sclerosis. CBD also has long received attention for therapeutic potential in the treatment of numerous neurological and psychiatric disorders. Our findings extend understanding of CBD's therapeutic profile to potential medical benefit for relapse prevention in substance use disorders.

\section{ACKNOWLEDGEMENTS}

This is publication number 29366 from the Scripps Research Institute. The CBD gel preparation was generously provided by Zynerba Pharmaceuticals, Inc, (Devon, PA) and AllTranz, Inc. (Lexington, KY). We thank the students Christine Chan, William Choy, Yunchen Ding, Li Huang, Tao Moua, Mark Sanderson-Cimino, and Angela Wong for assistance.

\section{AUTHOR CONTRIBUTIONS}

FW and ALS conceived the study. GGC, FW, and RMF designed the experiments. GGC and FW analyzed the data and wrote the manuscript. GGC and RMF conducted the behavioral tests. SLB developed and prepared the transdermal CBD gel formulation. TMK, DGS, and LHP performed tissue extraction and LC-MS assays of CBD brain levels. DCH performed the LC-MS assays of CBD plasma levels.

\section{ADDITIONAL INFORMATION}

The online version of this article (https://doi.org/10.1038/s41386-018-0050-8) contains supplementary material, which is available to authorized users.

Conflict of interest: The authors declare that they have no conflict of interest.

Funding: This research was supported by NIH Grants AA022082 (FW), AA021549 (FW), and DA039821 (FW).

\section{REFERENCES}

1. Wilkinson ST, Yarnell S, Radhakrishnan R, Ball SA, D'Souza DC. Marijuana legalization: impact on physicians and public health. Annu Rev Med. 2016;67:453-66.

2. Hurd YL. Cannabidiol: swinging the marijuana pendulum from 'Weed' to medication to treat the opioid epidemic. Trends Neurosci. 2017;40:124-7.

3. Scuderi C, De Filippis D, luvone T, Blasio A, Steardo A, Esposito G. Cannabidiol in medicine: a review of its therapeutic potential in CNS disorders. Phytother Res. 2009;23:597-602.

4. O'Connell BK, Gloss D, Devinsky O. Cannabinoids in treatment-resistant epilepsy: a review. Epilepsy Behav. 2017;70(Pt B):341-8.

5. Russo M, Naro A, Leo A, Sessa E, D'Aleo G, Bramanti $P$, et al. Evaluating sativex(R) in neuropathic pain management: a clinical and neurophysiological assessment in multiple sclerosis. Pain Med. 2016;17:1145-54.

6. Consroe P, Carlini EA, Zwicker AP, Avelinolacerda L. Interaction of cannabidiol and alcohol in humans. Psychopharmacology. 1979;66:45-50.

7. Morgan CJ, Das RK, Joye A, Curran HV, Kamboj SK. Cannabidiol reduces cigarette consumption in tobacco smokers: preliminary findings. Addict Behav. 2013;38:2433-6.

8. Katsidoni V, Anagnostou I, Panagis G. Cannabidiol inhibits the reward-facilitating effect of morphine: involvement of $5-\mathrm{HT} 1 \mathrm{~A}$ receptors in the dorsal raphe nucleus. Addict Biol. 2013;18:286-96.

9. Mahmud A, Gallant S, Sedki F, D'Cunha T, Shalev U. Effects of an acute cannabidiol treatment on cocaine self-administration and cue-induced cocaine seeking in male rats. J Psychopharmacol. 2016;31:96-104.

10. Parker LA, Burton P, Sorge RE, Yakiwchuk C, Mechoulam R. Effect of low doses of delta9-tetrahydrocannabinol and cannabidiol on the extinction of cocaineinduced and amphetamine-induced conditioned place preference learning in rats. Psychopharmacology. 2004;175:360-6.

11. Ren YH, Whittard J, Higuera-Matas A, Morris CV, Hurd YL. Cannabidiol, a nonpsychotropic component of cannabis, inhibits cue-induced heroin seeking and normalizes discrete mesolimbic neuronal disturbances. J Neurosci. 2009:29:14764-9.
12. Prud'homme M, Cata R, Jutras-Aswad D. Cannabidiol as an intervention for addictive behaviors: a systematic review of the evidence. Subst Abus. 2015;9:33-8.

13. American Psychiatric Association. Diagnostic and statistical manual of mental disorders. 5th ed. Arlington, VA: American Psychiatric Publishing; 2013.

14. Leshner Al. Addiction is a brain disease, and it matters. Science. 1997;278:45-7.

15. Campos AC, Ferreira FR, Guimaraes FS. Cannabidiol blocks long-lasting behavioral consequences of predator threat stress: possible involvement of 5HT1A receptors. J Psychiatr Res. 2012;46:1501-10.

16. Guimaraes FS, Chiaretti TM, Graeff FG, Zuardi AW. Antianxiety effect of cannabidiol in the elevated plus-maze. Psychopharmacology. 1990;100:558-9.

17. Campos AC, Ortega Z, Palazuelos J, Fogaca MV, Aguiar DC, Diaz-Alonso J, et al. The anxiolytic effect of cannabidiol on chronically stressed mice depends on hippocampal neurogenesis: involvement of the endocannabinoid system. Int J Neuropsychopharmacol. 2013;16:1407-19.

18. Marinho AL, Vila-Verde C, Fogaca MV, Guimaraes FS. Effects of intra-infralimbic prefrontal cortex injections of cannabidiol in the modulation of emotional behaviors in rats: contribution of $5 \mathrm{HT}(1) \mathrm{A}$ receptors and stressful experiences. Behav Brain Res. 2015;286:49-56.

19. Zanelati TV, Biojone C, Moreira FA, Guimaraes FS, Joca SRL. Antidepressant-like effects of cannabidiol in mice: possible involvement of 5-HT(1A) receptors. $\mathrm{Br} J$ Pharmacol. 2010;159:122-8.

20. Casarotto PC, Gomes FV, Resstel LB, Guimaraes FS. Cannabidiol inhibitory effect on marble-burying behaviour: involvement of $\mathrm{CB} 1$ receptors. Behav Pharmacol. 2010;21:353-8.

21. Gomes FV, Reis DG, Alves FHF, Correa FMA, Guimaraes FS, Resstel LBM. Cannabidiol injected into the bed nucleus of the stria terminalis reduces the expression of contextual fear conditioning via 5-HT1A receptors. J Psychopharmacol. 2012;26:104-13.

22. Guimaraes VM, Zuardi AW, Del Bel EA, Guimaraes FS. Cannabidiol increases Fos expression in the nucleus accumbens but not in the dorsal striatum. Life Sci. 2004;75:633-8.

23. Lemos Jl, Resstel LB, Guimaraes FS. Involvement of the prelimbic prefrontal cortex on cannabidiol-induced attenuation of contextual conditioned fear in rats. Behav Brain Res. 2010;207:105-11.

24. Koob GF, Volkow ND. Neurocircuitry of addiction. Neuropsychopharmacology. 2010;35:217-38.

25. luvone T, Esposito G, De Filippis D, Scuderi C, Steardo L. Cannabidiol: a promising drug for neurodegenerative disorders? Cns Neurosci \& Ther. 2009;15:65-75

26. Liput DJ, Hammell DC, Stinchcomb AL, Nixon K. Transdermal delivery of cannabidiol attenuates binge alcohol-induced neurodegeneration in a rodent model of an alcohol use disorder. Pharmacol Biochem Behav. 2013;111:120-7.

27. Crews FT, Boettiger CA. Impulsivity, frontal lobes and risk for addiction. Pharmacol Biochem Behav. 2009;93:237-47.

28. Agurell S, Carlsson S, Lindgren JE, Ohlsson A, Gillespie H, Hollister L. Interactions of delta 1-tetrahydrocannabinol with cannabinol and cannabidiol following oral administration in man. Assay of cannabinol and cannabidiol by mass fragmentography. Experientia. 1981;37:1090-2.

29. Merrick J, Lane B, Sebree T, Yaksh T, O'Neill C, Banks SL. Identification of psychoactive degradants of cannabidiol in simulated gastric and physiological fluid. Cannabis Cannabinoid Res. 2016;1:102-13.

30. Paudel KS, Hammell DC, Agu RU, Valiveti S, Stinchcomb AL. Cannabidiol bioavailability after nasal and transdermal application: effect of permeation enhancers. Drug Dev Ind Pharm. 2010;36:1088-97.

31. Kufahl PR, Martin-Fardon R, Weiss F. Enhanced sensitivity to attenuation of conditioned reinstatement by the mGluR(2/3) agonist LY379268 and increased functional activity of $\operatorname{mGluR}(2 / 3)$ in rats with a history of ethanol dependence. Neuropsychopharmacology. 2011;36:2762-73.

32. Martin-Fardon R, Baptista MA, Dayas CV, Weiss F. Dissociation of the effects of MTEP [3-[(2-methyl-1,3-thiazol-4-yl)ethynyl]piperidine] on conditioned reinstatement and reinforcement: comparison between cocaine and a conventional reinforcer. J Pharmacol Exp Ther. 2009;329:1084-90.

33. Zhao $Y$, Weiss F, Zorrilla EP. Remission and resurgence of anxiety-like behavior across protracted withdrawal stages in ethanol-dependent rats. Alcohol Clin Exp Res. 2007;31:1505-15.

34. Pattij T, Janssen MC, Schepers I, Gonzalez-Cuevas G, de Vries TJ, Schoffelmeer AN. Effects of the cannabinoid $\mathrm{CB} 1$ receptor antagonist rimonabant on distinct measures of impulsive behavior in rats. Psychopharmacology. 2007;193:85-96.

35. Baptista MA, Martin-Fardon R, Weiss F. Preferential effects of the metabotropic glutamate 2/3 receptor agonist LY379268 on conditioned reinstatement versus primary reinforcement: comparison between cocaine and a potent conventional reinforcer. J Neurosci. 2004;24:4723-7.

36. Ciccocioppo R, Martin-Fardon R, Weiss F. Stimuli associated with a single cocaine experience elicit long-lasting cocaine-seeking. Nat Neurosci. 2004;7:495-6. 
37. Ciccocioppo R, Sanna PP, Weiss F. Cocaine-predictive stimulus induces drugseeking behavior and neural activation in limbic brain regions after multiple months of abstinence: reversal by $D(1)$ antagonists. Proc Natl Acad Sci USA. 2001b;98:1976-81.

38. Martin-Fardon R, Weiss F. Perseveration of craving: effects of stimuli conditioned to drugs of abuse versus conventional reinforcers differing in demand. Addict Biol. 2017;22:923-32.

39. Weiss F, Maldonado-Vlaar CS, Parsons LH, Kerr TM, Smith DL, Ben-Shahar O. Control of cocaine-seeking behavior by drug-associated stimuli in rats: effects on recovery of extinguished operant-responding and extracellular dopamine levels in amygdala and nucleus accumbens. Proc Natl Acad Sci USA. 2000;97:4321-6.

40. Weiss F, Martin-Fardon R, Ciccocioppo R, Kerr TM, Smith DL, Ben-Shahar O. Enduring resistance to extinction of cocaine-seeking behavior induced by drugrelated cues. Neuropsychopharmacology. 2001;25:361-72.

41. Ciccocioppo R, Angeletti S, Weiss F. Long-lasting resistance to extinction of response reinstatement induced by ethanol-related stimuli: role of genetic ethanol preference. Alcohol Clin Exp Res. 2001;25:1414-9.

42. Katner SN, Magalong JG, Weiss F. Reinstatement of alcohol-seeking behavior by drug-associated discriminative stimuli after prolonged extinction in the rat. Neuropsychopharmacology. 1999;20:471-9.

43. Katner SN, Weiss F. Ethanol-associated olfactory stimuli reinstate ethanol-seeking behavior after extinction and modify extracellular dopamine levels in the nucleus accumbens. Alcohol Clin Exp Res. 1999;23:1751-60.

44. Liu X, Weiss F. Reversal of ethanol-seeking behavior by D1 and D2 antagonists in an animal model of relapse: differences in antagonist potency in previously ethanol-dependent versus nondependent rats. J Pharmacol Exp Ther. 2002;300:882-9.

45. Sidhpura N, Weiss F, Martin-Fardon R. Effects of the mGlu2/3 agonist LY379268 and the mGlu5 antagonist MTEP on ethanol seeking and reinforcement are differentially altered in rats with a history of ethanol dependence. Biol Psychiatry. 2010;67:804-11.

46. Crombag HS, Bossert JM, Koya E, Shaham Y. Context-induced relapse to drug seeking: a review. Philos Trans R Soc Lond B Biol Sci. 2008;363:3233-43.

47. Aujla H, Cannarsa R, Romualdi P, Ciccocioppo R, Martin-Fardon R, Weiss F. Modification of anxiety-like behaviors by nociceptin/orphanin FQ (N/OFQ) and time-dependent changes in N/OFQ-NOP gene expression following ethanol withdrawal. Addict Biol. 2013;18:467-79.

48. Braconi S, Sidhpura N, Aujla H, Martin-Fardon R, Weiss F, Ciccocioppo R. Revisiting intragastric ethanol intubation as a dependence induction method for studies of ethanol reward and motivation in rats. Alcohol Clin Exp Res. 2010;34:538-44.

49. Folch-Pi J, Lees M, Stanley GHS. A simple method for the isolation and purification of total lipids from animal tissue. J Biol Chem. 1957;226:497-509.

50. Martin-Fardon R, Weiss F. Modeling relapse in animals. Curr Top Behav Neurosci. 2013;13:403-32.

51. Chen YW, Fiscella KA, Bacharach SZ, Tanda G, Shaham Y, Calu DJ. Effect of yohimbine on reinstatement of operant responding in rats is dependent on cue contingency but not food reward history. Addict Biol. 2015;20:690-700.

52. Dick DM, Smith G, Olausson P, Mitchell SH, Leeman RF, O'Malley SS, et al. Understanding the construct of impulsivity and its relationship to alcohol use disorders. Addict Biol. 2010;15:217-26.

53. Verdejo-Garcia A, Lawrence AJ, Clark L. Impulsivity as a vulnerability marker for substance-use disorders: Review of findings from high-risk research, problem gamblers and genetic association studies. Neurosci Biobehav Rev. 2008;32:777-810.

54. Stevens L, Goudriaan AE, Verdejo-Garcia A, Dom G, Roeyers H, Vanderplasschen W. Impulsive choice predicts short-term relapse in substance-dependent individuals attending an in-patient detoxification programme. Psychol Med. 2015;45:2083-93.

55. Oberlin BG, Grahame NJ. High-alcohol preferring mice are more impulsive than low-alcohol preferring mice as measured in the delay discounting task. Alcohol Clin Exp Res. 2009;33:1294-303.

56. Poulos CX, Parker JL, Le DA. Increased impulsivity after injected alcohol predicts later alcohol consumption in rats: evidence for "loss-of-control drinking" and marked individual differences. Behav Neurosci. 1998;112:1247-57.

57. Wilhelm CJ, Mitchell SH. Rats bred for high alcohol drinking are more sensitive to delayed and probabilistic outcomes. Genes Brain Behav. 2008;7:705-13.

58. Martin-Fardon R, Weiss F. Modeling relapse in animals. Curr Top Behav Neurosci. 2013;13:403-432.

59. Mantsch JR, Baker DA, Funk D, Le AD, Shaham Y. Stress-induced reinstatement of drug seeking: 20 years of progress. Neuropsychopharmacology. 2016;41:335-56

60. Epstein DH, Preston KL, Stewart J, Shaham Y. Toward a model of drug relapse: an assessment of the validity of the reinstatement procedure. Psychopharmacology. 2006;189:1-16.

61. de Carvalho CR, Takahashi RN. Cannabidiol disrupts the reconsolidation of contextual drug-associated memories in Wistar rats. Addict Biol. 2017;22:742-51.
62. Crippa JAS, Derenusson GN, Ferrari TB, Wichert-Ana L, Duran FLS, Martin-Santos $R$, et al. Neural basis of anxiolytic effects of cannabidiol (CBD) in generalized social anxiety disorder: a preliminary report. J Psychopharmacol. 2011;25:121-30.

63. Bergamaschi MM, Queiroz RHC, Chagas MHN, de Oliveira DCG, De Martinis BS, Kapczinski F, et al. Cannabidiol reduces the anxiety induced by simulated public speaking in treatment-naive social phobia patients. Neuropsychopharmacology. 2011;36:1219-26.

64. Stern CA, Gazarini L, Takahashi RN, Guimaraes FS, Bertoglio L. On disruption of fear memory by reconsolidation blockade: evidence from cannabidiol treatment Neuropsychopharmacology. 2012;37:2132-42.

65. Arndt $\mathrm{DL}$, de Wit $\mathrm{H}$. Cannabidiol does not dampen responses to emotional stimuli in healthy adults. Cannabis Cannabinoid Res. 2017;2:105-13.

66. ElBatsh MM, Assareh N, Marsden CA, Kendall DA. Anxiogenic-like effects of chronic cannabidiol administration in rats. Psychopharmacology. 2012;221:239-47.

67. Campos AC, Moreira FA, Gomes FV, Del Bel EA, Guimaraes FS. Multiple mechanisms involved in the large-spectrum therapeutic potential of cannabidiol in psychiatric disorders. Philos Trans R Soc Lond B Biol Sci. 2012;367:3364-78.

68. Parsons LH, Hurd YL. Endocannabinoid signalling in reward and addiction. Nat Rev Neurosci. 2015;16:579-94.

69. Ashton $\mathrm{CH}$, Moore PB. Endocannabinoid system dysfunction in mood and related disorders. Acta Psychiatr Scand. 2011;124:250-61.

70. Moreira FA, Wotjak CT. Cannabinoids and anxiety. Curr Top Behav Neurosci. 2010;2:429-50.

71. Riebe CJ, Wotjak CT. Endocannabinoids and stress. Stress. 2011;14:384-97.

72. Kathmann M, Flau K, Redmer A, Trankle C, Schlicker E. Cannabidiol is an allosteric modulator at mu- and delta-opioid receptors. Naunyn Schmiede Arch Pharmacol. 2006;372:354-61.

73. Gururajan A, Taylor DA, Malone DT. Cannabidiol and clozapine reverse MK-801induced deficits in social interaction and hyperactivity in Sprague-Dawley rats. J Psychopharmacol. 2012;26:1317-32.

74. Russo EB, Burnett A, Hall B, Parker KK. Agonistic properties of cannabidiol at 5HT1a receptors. Neurochem Res. 2005;30:1037-43.

75. Campos AC, Guimaraes FS. Involvement of 5HT1A receptors in the anxiolytic-like effects of cannabidiol injected into the dorsolateral periaqueductal gray of rats. Psychopharmacology. 2008;199:223-30.

76. Fogaca MV, Reis FM, Campos AC, Guimaraes FS. Effects of intra-prelimbic prefrontal cortex injection of cannabidiol on anxiety-like behavior: involvement of 5 HT1 A receptors and previous stressful experience. Eur Neuropsychopharmacol. 2014;24:410-9.

77. Gomes FV, Resstel LBM, Guimaraes FS. The anxiolytic-like effects of cannabidiol injected into the bed nucleus of the stria terminalis are mediated by $5-\mathrm{HT} 1 \mathrm{~A}$ receptors. Psychopharmacology. 2011;213:465-73.

78. Resstel LB, Tavares RF, Lisboa SF, Joca SR, Correa FM, Guimaraes FS. 5-HT1A receptors are involved in the cannabidiol-induced attenuation of behavioural and cardiovascular responses to acute restraint stress in rats. $\mathrm{Br} \mathrm{J}$ Pharmacol. 2009;156:181-8.

79. Mandyam CD, Koob GF. The addicted brain craves new neurons: putative role for adult-born progenitors in promoting recovery. Trends Neurosci. 2012;35:250-60.

80. Jiang W, Zhang Y, Xiao L, Van Cleemput J, Ji SP, Bai G, et al. Cannabinoids promote embryonic and adult hippocampus neurogenesis and produce anxiolytic- and antidepressant-like effects. J Clin Invest. 2005;115:3104-16.

81. Wolf SA, Bick-Sander A, Fabel K, Leal-Galicia P, Tauber S, Ramirez-Rodriguez G, et al. Cannabinoid receptor CB1 mediates baseline and activity-induced survival of new neurons in adult hippocampal neurogenesis. Cell Commun Signal. 2010;8:12.

82. Amlung M, Vedelago L, Acker J, Balodis I, MacKillop J. Steep delay discounting and addictive behavior: a meta-analysis of continuous associations. Addiction. 2017;112:51-62.

83. MacKillop J, Kahler CW. Delayed reward discounting predicts treatment response for heavy drinkers receiving smoking cessation treatment. Drug Alcohol Depend. 2009;104:197-203.

84. Crews FT, Boettiger CA. Impulsivity, frontal lobes and risk for addiction. Pharmacol Biochem Behav. 2009; 93:237-247.

85. Hampson AJ, Grimaldi M, Axelrod J, Wink D. Cannabidiol and (-)delta(9)-tetrahydrocannabinol are neuroprotective antioxidants. Proc Natl Acad Sci USA 1998;95:8268-73.

86. Nixon K, Crews FT. Binge ethanol exposure decreases neurogenesis in adult rat hippocampus. J Neurochem. 2002;83:1087-93.

87. Esposito G, Scuderi C, Valenza M, Togna Gl, Latina V, De Filippis D, et al. Cannabidiol reduces Abeta-induced neuroinflammation and promotes hippocampal neurogenesis through PPARgamma involvement. PLoS ONE. 2011;6:e28668.

88. Fagherazzi EV, Garcia VA, Maurmann N, Bervanger T, Halmenschlager LH, Busato $\mathrm{SB}$, et al. Memory-rescuing effects of cannabidiol in an animal model of cognitive impairment relevant to neurodegenerative disorders. Psychopharmacology. 2012;219:1133-40. 